\title{
Qualidade pós-colheita de frutos de meloeiro fertirrigado com diferentes doses de potássio e lâminas de irrigação ${ }^{1}$
}

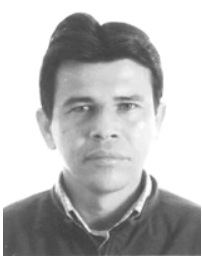

Manuel A. N. Vásquez ${ }^{2}$, Marcos V. Folegatti ${ }^{3}$, Nildo da S. Dias ${ }^{3}$ \& Valdemício F. de Sousa ${ }^{4}$

\author{
1 Parte da tese de doutorado do primeiro autor, financiada pela FAPESP \\ ${ }^{2}$ ESALQ/USP, LER, CP 09, CEP 13418-900, Piracicaba, SP. Fone: (019) 429 -4217. E-mail: manava98@yahoo.com.br (Foto) \\ ${ }^{3}$ ESALQ/USP, LER. E-mail:mvfolega@esalq.usp.br; nisdias@esalq.usp.br \\ ${ }^{4}$ EMBRAPA Meio Norte, CP 01, CEP 64006-220, Teresina, PI. E-mail: vfsousa@cpamn.embrapa.br
}

Protocolo 83 - 16/6/2003 - Aprovado em 18/6/2004

\begin{abstract}
Resumo: Em função de se desejar avaliar a qualidade pós-colheita de frutos de meloeiro fertirrigado com diferentes níveis de irrigação e doses de potássio, conduziu-se um estudo em ambiente protegido na área experimental do Departamento de Engenharia Rural da ESALQ/USP, localizado no município de Piracicaba, SP. Os tratamentos foram compostos da combinação de três fatores: duas posições de instalação das linhas porta-gotejadores (superficial, $P_{1}=0$ e enterrado $P_{2}=$ $0,2 \mathrm{~m}$ da superfície do solo), três lâminas de irrigação $\left(\mathrm{L}_{1}=33 \% ; \mathrm{L}_{2}=67 \%\right.$ e $\mathrm{L}_{3}=100 \%$ da evaporação diária do mini-tanque evaporimétrico) e quatro doses de potássio $\left(\mathrm{K}_{0}=0 ; \mathrm{K}_{1}=6\right.$; $\mathrm{K}_{2}=9$ e $_{3}=12 \mathrm{~g}$ de $\mathrm{K}_{2} \mathrm{O}$ por planta). $\mathrm{O}$ delineamento experimental adotado foi o de blocos casu-alizados completos com 3 repetições e os fatores estudados foram arranjados no esquema fatorial de $4 \times 3 \times 2$. Os resultados mostram que a dose de $9 \mathrm{~g}$ de $\mathrm{K}_{2} \mathrm{O}$ por planta e a lâmina de $269,6 \mathrm{~mm}$ proporcionaram maiores valores de sólidos solúveis totais. $\mathrm{O} \mathrm{pH}$ dos frutos de melão cresceu com o aumento das doses de $\mathrm{K}_{2} \mathrm{O}$ até a lâmina de $269,60 \mathrm{~mm} \mathrm{~L}_{2}$ e linhas porta-gotejadores enterradas. Houve um incremento na acidez total titulável com o aumento das doses de potássio, até $9 \mathrm{~g}$ de $\mathrm{K}_{2} \mathrm{O}$ por planta e, também, ligeiro decréscimo quando se aumentou o nível de irrigação para as linhas de porta-gotejadores enterradas.
\end{abstract}

Palavras-chave: manejo da fertirrigação, porta-gotejadores, Cucumis melo L.

\section{Postharvest quality of melon fertirrigated with different doses of potassium and irrigation levels}

\begin{abstract}
To evaluate the postharvest quality of melon, fertirrigated by sufarce or subsurface drip emitters, with different potassium doses and irrigation water depths, a study was carried out under greenhouse conditions, in the experimental field of Departamento de Engenharia Rural da Escola Superior de Agricultura "Luiz de Queiroz"- USP, Piracicaba, SP. Treatments were composed of the combinations of three factors: two installation dripper depths $(0$ and $0.2 \mathrm{~m})$, three irrigation levels $(1$, $2 / 3$ and $1 / 3$ of daily evaporation, measured by a modifield pan) and four potassium doses $(0 ; 6 ; 9 \mathrm{e}$ $12 \mathrm{~g} \mathrm{~K}_{2} \mathrm{O}$ per plant). The experiment was conducted in randomized blocks, with three repetitions, arranged in factorial design: $2 \times 3 \times 4$. Results showed that the dose of $9 \mathrm{~g} \mathrm{~K}_{2} \mathrm{O}$ and irrigation level of $269,60 \mathrm{~mm}$ ( $2 / 3$ evaporation) provided higher values of total soluble solid content. The $\mathrm{pH}$ of the melon fruit increased with potassium dosage for subsurface drip irrigation. There was increment of the total titrable acidity with increasing potassium dose until $9 \mathrm{~g}$ of $\mathrm{K}_{2} \mathrm{O}$ for each plant; with a slight decrease when the irrigation level for subsurface drip irrigation was increased.
\end{abstract}

Key words: fertirrigation management, dripers on line, Cucumis melo L.

\section{INTRODUÇÃO}

A produtividade e a qualidade dos frutos do meloeiro podem ser influenciadas por diversos fatores, como nutrição mineral, umidade do solo (Wells \& Nugent, 1980), fatores genéticos (Lippert \& Legg, 1972), condições climáticas (Browkamp et al., 1978), reguladores de crescimento (Bosland et al., 1979) e época de colheita (Bleinroth, 1994). A qualidade do 
melão está associada ao teor de sólidos solúveis totais, $\mathrm{pH}$ e acidez total titulável, constituindo-se em características decisivas na comercialização dos frutos.

A resposta do meloeiro à irrigação está bem documentada (Loy \& Wells, 1975; Bhella, 1988; Phene \& Beale, 1976; Clough et al., 1990), visto que a freqüência e a oportunidade de aplicação da água influenciam sobremaneira a qualidade do fruto (Bhella \& Wilcox, 1986; Bar-Yosef \& Sagiv, 1986a e 1986b). O potássio tem papel relevante no rendimento do melão, mas o excesso pode causar desenvolvimento vegetativo de pouco vigor, frutos de menor peso médio e maturação prematura, diminuindo a assimilação de fósforo (Hariprakasa \& Srinivas, 1990; Pinto et al., 1995).

Nas regiões onde o clima não favorece o cultivo do meloeiro, é possível se desenvolver técnicas de exploração em ambientes protegidos sob fertirrigação, permitindo a obtenção de produtividades elevadas e de frutos de boa qualidade, mas se torna necessário desenvolver tecnologias na área de manejo de água, solo, nutriente e cultura, capazes de maximizar ainda mais a utilização de água e de fertilizantes, obtendo-se assim melhor retorno econômico.

A aplicação de água e nutrientes por gotejamento melhora a qualidade das culturas e promove a economia de recursos hídricos e preservação do meio ambiente. Entretanto, são poucas as informações referentes ao seu manejo, sobretudo quando associado à fertirrigação por gotejamento subsuperficial, com lâminas de irrigação e dosagens adequadas de nutrientes, requerendo mais pesquisas.

O potássio é extraído pelo meloeiro em maiores quantidades que o dos outros nutrientes ( $385 \mathrm{~kg}$ de potássio ha ${ }^{-1}$ ) mantendose sua necessidade depois que os frutos alcançam tamanho normal, até completar a maturação, para só então conseguir boa qualidade (Bar-Yosef, 1999).

Com relação à necessidade hídrica da cultura do melão, Mancina (1977) verificou que a maior produção foi obtida com aplicações diárias de lâminas correspondentes a $80 \%$ da evaporação do tanque classe A. Coelho et al. (1978) aplicando lâminas de água por gotejamento na cultura do melão, obtiveram maior produção com lâminas equivalentes a 75 e 100\% da evaporação do tanque classe $\mathrm{A}$, com intervalos de irrigação de 2 dias. Dusi (1992) recomenda, para o meloeiro, irrigação por gotejamento, no período de semeadura até a emergência das plantas, com freqüência de aplicação de água diária e de baixa intensidade. No período de frutificação esta freqüência pode ser reduzida, porém com maior intensidade de irrigação. Sob condições protegidas e de campo, em solos arenosos Sousa et al. (1999) obtiveram melhores respostas com aplicação de água na freqüência entre um e dois dias.

Levando-se em consideração esses aspectos objetivouse, com este trabalho, estudar os efeitos de duas posições de instalação das linhas porta-gotejadores, três lâminas de irrigação e quatro dosagens de potássio aplicadas via fertirrigação no teor de sólidos solúveis totais ( ${ }^{\circ} \mathrm{Brix}$ ), $\mathrm{pH}$ e acidez total titulável (ATT) de frutos de meloeiro em ambiente protegido.

\section{MATERIAL E MÉTODOS}

O experimento foi conduzido na área experimental do Departamento de Engenharia Rural da Escola Superior de Agricultura "Luiz de Queiroz" - USP, Piracicaba, SP, em um ambiente protegido de $420 \mathrm{~m}^{2}(15 \times 28 \mathrm{~m})$, localizado a $22^{\circ} 42^{\prime} 30^{\prime}$ " de latitude Sul, $47^{0} 38^{\prime} 00^{\prime}$ ' de longitude a Oeste de Greenwich e $576 \mathrm{~m}$ de altitude, no período de 16 de setembro de 2001 a 17 de janeiro de 2002. O ambiente protegido utilizado possuía dois vãos, com estrutura metálica galvanizada, altura na parte central de 4,6 m e pé direito de 3,0 m, constituído de 4 janelas frontais, cobertas com um filme de polietileno transparente de alta densidade (PEAD), com aditivo ultravioleta e espessura de $150 \mu \mathrm{m}$. Suas laterais foram fechadas com tela plástica de proteção tipo clarite $50 \%$, com tratamento ultravioleta, transparente e revestida de cortinas para regular as temperaturas e fluxo de ar.

O solo foi classificado como Latossolo Vermelho-Amarelo, fase arenosa, denominada "Série Sertãozinho"; do qual se retiraram amostras da camada de $0-20 \mathrm{~cm}$ para as análises químicas (Tabela 1) e físicas (Tabela 2).

Tabela 1. Características químicas do solo

\begin{tabular}{|c|c|c|c|c|c|c|c|c|c|c|}
\hline Camada & $\mathrm{pH}$ & $\mathrm{MO}^{*}$ & $P$ & S & $\mathrm{K}^{+}$ & $\mathrm{Ca}^{2+}$ & $\mathrm{Mg}^{2+}$ & $\mathrm{Al}^{3+}+\mathrm{I}$ & СТC & $\mathrm{V} \mathrm{m}$ \\
\hline $\mathrm{Cm}$ & $\left(\mathrm{CaCl}_{2}\right)$ & $\mathrm{g} \mathrm{kg}^{-1}$ & & $\mathrm{dm}^{-3}$ & & & $\mathrm{mmc}$ & $\mathrm{dm}^{-3}$ & & $\%$ \\
\hline $0-20$ & 4,5 & 11 & 5 & 18 & 0,6 & 10 & 5 & 22 & 37,6 & $41 \quad 11$ \\
\hline
\end{tabular}

Tabela 2. Características físicas* do solo

\begin{tabular}{|c|c|c|c|c|c|c|c|c|}
\hline \multirow{2}{*}{ Camada } & \multirow{2}{*}{$\mathrm{CC}$} & \multirow{2}{*}{ PMP } & \multirow{2}{*}{$\mathrm{dg}$} & \multicolumn{3}{|c|}{$\mathrm{FG}$} & \multirow{2}{*}{ Floculação } & \multirow{2}{*}{ Textura } \\
\hline & & & & \multirow{2}{*}{ Argila } & \multirow{2}{*}{$\begin{array}{l}\text { Silte } \\
\mathrm{g} \mathrm{kg}^{-1}\end{array}$} & \multirow{2}{*}{ Areia } & & \\
\hline $\mathrm{cm}$ & $\mathrm{cm}^{3}$ & $\mathrm{~cm}^{-3}$ & $\mathrm{~kg} \mathrm{dm} \mathrm{m}^{-3}$ & & & & $\%$ & \\
\hline $0-20$ & 0,194 & 0,125 & 1,4 & 280 & 80 & 640 & 100 & $\begin{array}{l}\text { Franco- } \\
\text { arenoso }\end{array}$ \\
\hline
\end{tabular}

Com base no resultado da análise química do solo, foram aplicados e incorporados ao solo 7,12 $\mathrm{t} \mathrm{ha}^{-1}$ de calcário dolomítico 60 dias antes do transplantio das mudas de melão, para elevar a saturação por bases a $80 \%$ (Raij et al., 1996). A adubação de fundação foi feita por cova com $12 \mathrm{~kg}$ de esterco de bovino curtido (Kiehl, 1985) e $0,052 \mathrm{~kg}$ de $\mathrm{P}_{2} \mathrm{O}_{5}$ na forma de termofosfatado.

Os tratamentos se compunham da combinação de três fatores: duas posições de instalação das linhas de portagotejadores (superficial, $\mathrm{P}_{1}$ e enterrado, $\mathrm{P}_{2}=0,2 \mathrm{~m}$ da superfície do solo), três lâminas de irrigação $\left(\mathrm{L}_{1}=33 \% ; \mathrm{L}_{2}=67 \%\right.$ e $\mathrm{L}_{3}=$ $100 \%$ a evaporação diária do mini-tanque evaporimétrico) e quatro doses de potássio $\left(\mathrm{K}_{1}=0 ; \mathrm{K}_{2}=6 ; \mathrm{K}_{3}=9\right.$ e $\mathrm{K}_{4}=12 \mathrm{~g}$ de $\mathrm{K}_{2} \mathrm{O}$ por planta). $\mathrm{O}$ uso de mini-tanque evaporimétrico (tanque classe A reduzido) em ambientes protegidos para estimativa da evaporação é recomendado com base em estudos realizados por Medeiros et al. (1997). As dosagens de potássio foram definidas a partir de recomendações médias para fertirrigação (Pinto et al, 1995; Bar-Yosef, 1999). O delineamento estatístico adotado foi o de blocos casualizados completos com 3 repetições e os fatores estudados foram arranjados no esquema fatorial de $4 \times 3 \times 2$. 
As lâminas de irrigação foram determinadas em função da evaporação diária do mini-tanque evaporimétrico com dimensões de $0,60 \mathrm{~m}$ de diâmetro e $0,25 \mathrm{~m}$ de altura, instalado no terço médio dentro do ambiente protegido. Aplicaram-se, até o final do ciclo, as seguintes lâminas de irrigação: $\mathrm{L}_{1}=$ 137,$72 ; \mathrm{L}_{2}=279,60 \mathrm{e} \mathrm{L}_{3}=417,32 \mathrm{~mm}$.

Cada parcela experimental foi constituída de valetas (comprimento $=3,6 \mathrm{~m}$, largura $=0,6 \mathrm{~m}$ e profundidade $=0,40 \mathrm{~m}$ ), espaçadas $0,5 \mathrm{~m}$, as quais foram protegidas nas laterais com polietileno inerte, evitando possível contaminação entre os tratamentos. Em cada parcela foram cultivadas sementes do melão reticulatos (Cucumis melo L.), cultivar Bônus II, com duas fileiras de plantas, espaçadas $0,6 \mathrm{~m}$ entre plantas e $0,20 \mathrm{~m}$ entre fileiras, em esquema alternado, totalizando 13 plantas por cova, sendo 9 plantas úteis, enquanto 2 de cada extremo funcionaram como bordadura. As plantas foram conduzidas em espaldeiras verticais de $2 \mathrm{~m}$ de altura e desbrotando os excessos de brotações laterais, com posterior tratamento fitossanitário, evitando a entrada de patógenos pelos ferimentos. Os frutos foram recebidos em cestas plásticas (enredados), presos à linha de arame, para ajudar a sustentação nas plantas e conferir melhor qualidade de casca.

As adubações foram realizadas com freqüência de dois dias em fertirrigação à base de $150 \mathrm{~kg} \mathrm{ha}^{-1} \mathrm{de} \mathrm{N}$ para cada tratamento e segundo as dosagens de potássio estabelecidas, nas formas de nitrato de amônio e nitrato de potássio, de acordo com a marcha de absorção da cultura, durante seu ciclo (Bar-Yosef, 1999).

O sistema de irrigação adotado foi o de gotejamento, com emissores do tipo autocompensante e vazão nominal de $1,6 \mathrm{~L} \mathrm{~h}^{-1}$ espaçados $0,30 \mathrm{~m}$ e dispostos no centro das duas fileiras de plantas, auxiliados por um microcontrolador Basic Step e um periférico, provido de válvulas tipo solenóide, possibilitando o fluxo à rede hidráulica de 24 trechos de polietileno com $13 \mathrm{~mm}$ de diâmetro nominal, comprimento entre 7,2 e 37,6 m e pressão nominal de $150 \mathrm{kPa}$.

A polinização foi melitófila, mantendo um enxame de abelhas dentro do ambiente protegido entre os 35 e 55 dias após o transplantio (DAT). A colheita dos frutos foi realizada aos 99 DAT, quando atingiram o ponto de maturação fisiológica, ou seja, mudança de coloração da casca para acinzentada e rendilhamento em volta do pedúnculo.

Para avaliar a qualidade pós-colheita dos frutos, selecionouse um fruto comercial para cada planta dentre 4 plantas por tratamento. Avaliaram-se as seguintes características: teor de sólidos solúveis totais, medidos por meio de um refratômetro digital de bolso (resolução de 0,2 ), expressos em ${ }^{\circ} \mathrm{Brix} ; \mathrm{pH}$, medido com um pehagâmetro digital de bancada e a acidez total titulável (ATT), determinada com $\mathrm{NaOH} 0,1 \mathrm{~N}$ até o $\mathrm{pH}$ atingir 8,1 e expressados em $\%$ de ácido málico.

\section{RESULTADOS E DISCUSSÃO}

Os conteúdos médios de sólidos solúveis totais ( $\left.{ }^{\circ} \mathrm{Brix}\right), \mathrm{pH}$ e acidez total titulável (ATT) para as 24 combinações entre os níveis de cada fator foram muito dispersos e estão dispostos na Tabela 3. A combinação $\mathrm{P}_{1} \mathrm{~L}_{2} \mathrm{~K}_{2}$ alcançou maior ${ }^{\circ} \mathrm{Brix}$ com média de 13,25 e o menor ${ }^{\circ}$ Brix dos frutos ocorreu na
Tabela 3 Médias dos teores de sólidos solúveis totais, $\mathrm{pH}$ e acidez total titulável em frutos de meloeiro, em função de diferentes doses de potássio, lâminas de irrigação e posição das linhas porta-gotejadores*

\begin{tabular}{|c|c|c|c|c|}
\hline LI & $\mathrm{K}_{2} \mathrm{O}$ & SST & \multirow{2}{*}{$\mathrm{pH}$} & ATT \\
\hline $\mathrm{mm}$ & g planta $^{-1}$ & ${ }^{o}$ Brix & & $\mathrm{mg} \mathrm{kg}^{-1}$ \\
\hline
\end{tabular}

Gotejamento Superficial

\begin{tabular}{|c|c|c|c|c|}
\hline \multirow{4}{*}{$\mathrm{L}_{1}$} & $\mathrm{~K}_{0}=0$ & 6,99 & 6,19 & 0,089 \\
\hline & $\mathrm{K}_{1}=6$ & 11,25 & 6,05 & 0,112 \\
\hline & $\mathrm{K}_{2}=9$ & 11,13 & 6,20 & 0,157 \\
\hline & $\mathrm{K}_{3}=12$ & 10,13 & 6,04 & 0,118 \\
\hline \multirow[t]{2}{*}{ Média } & & 9,88 & 6,12 & 0,119 \\
\hline & $\mathrm{K}_{0}=0$ & 10,88 & 6,04 & 0,155 \\
\hline \multirow{3}{*}{$\mathrm{L}_{2}$} & $\mathrm{~K}_{1}=6$ & 10,30 & 6,07 & 0,132 \\
\hline & $\mathrm{K}_{2}=9$ & 13,25 & 6,20 & 0,121 \\
\hline & $\mathrm{K}_{3}=12$ & 9,81 & 6,31 & 0,098 \\
\hline \multirow[t]{2}{*}{ Média } & & 11,06 & 6,16 & 0,126 \\
\hline & $\mathrm{K}_{0}=0$ & 8,73 & 6,20 & 0,102 \\
\hline \multirow[t]{3}{*}{$\mathrm{L}_{3}$} & $\mathrm{~K}_{1}=6$ & 9,00 & 6,10 & 0,083 \\
\hline & $\mathrm{K}_{2}=9$ & 7,06 & 6,22 & 0,114 \\
\hline & $\mathrm{K}_{3}=12$ & 9,50 & 6,37 & 0,095 \\
\hline \multicolumn{2}{|l|}{ Média } & 8,57 & 6,22 & 0,098 \\
\hline \multicolumn{2}{|c|}{ Média Global } & $9,84 \mathrm{~A}$ & $6,17 \mathrm{~A}$ & $0,114 \mathrm{~A}$ \\
\hline
\end{tabular}

Gotejamento Enterrado

\begin{tabular}{|c|c|c|c|c|}
\hline \multirow{4}{*}{$\mathrm{L}_{1}$} & $\mathrm{~K}_{0}=0$ & 7,75 & 6,12 & 0,102 \\
\hline & $\mathrm{K}_{1}=6$ & 10,13 & 6,42 & 0,114 \\
\hline & $\mathrm{K}_{2}=9$ & 11,34 & 6,02 & 0,110 \\
\hline & $\mathrm{K}_{3}=12$ & 9,31 & 6,41 & 0,125 \\
\hline \multirow[t]{2}{*}{ Média } & & 9,63 & 6,24 & 0,113 \\
\hline & $\mathrm{K}_{0}=0$ & 8,16 & 6,42 & 0,083 \\
\hline \multirow{3}{*}{$\mathrm{L}_{2}$} & $\mathrm{~K}_{1}=6$ & 10,38 & 6,37 & 0,122 \\
\hline & $\mathrm{K}_{2}=9$ & 8,91 & 6,09 & 0,110 \\
\hline & $\mathrm{K}_{3}=12$ & 10,13 & 6,51 & 0,080 \\
\hline \multirow[t]{2}{*}{ Média } & & 9,40 & 6,35 & 0,099 \\
\hline & $\mathrm{K}_{0}=0$ & 10,53 & 6,12 & 0,109 \\
\hline \multirow{3}{*}{$\mathrm{L}_{3}$} & $\mathrm{~K}_{1}=6$ & 9,13 & 6,16 & 0,089 \\
\hline & $\mathrm{K}_{2}=9$ & 8,75 & 6,43 & 0,099 \\
\hline & $\mathrm{K}_{3}=12$ & 8,75 & 6,00 & 0,105 \\
\hline \multicolumn{2}{|l|}{ Média } & 9,29 & 6,18 & 0,101 \\
\hline \multicolumn{2}{|c|}{ Tédia Global } & $9,44 \mathrm{~A}$ & $6,26 \mathrm{~B}$ & $0,104 \mathrm{~A}$ \\
\hline
\end{tabular}

combinação $\mathrm{P}_{1} \mathrm{~L}_{1} \mathrm{~K}_{0}$, com média de 6,99 . Os valores de $\mathrm{pH}$ dos frutos de melão variaram entre 6,43 e 6 representados pelas combinações $\mathrm{K}_{2} \mathrm{~L}_{3} \mathrm{P}_{2}$ e $\mathrm{K}_{3} \mathrm{~L}_{3} \mathrm{P}_{2}$, respectivamente, enquanto a ATT variou entre 0,157 e $0,080 \mathrm{mg}$ ácido málico anidro por 100 $\mathrm{mL}$ de suco representados pelas combinações $\mathrm{P}_{1} \mathrm{~L}_{1} \mathrm{~K}_{2}$ e $\mathrm{P}_{2} \mathrm{~L}_{2} \mathrm{~K}_{3}$, respectivamente.

Em razão dos resultados da análise de variância serem estatisticamente significativos pelo teste de $\mathrm{F}(\mathrm{P}<0,01)$ apenas para os parâmetros de qualidade ${ }^{\circ} \mathrm{Brix}$ e $\mathrm{pH}$ do fruto de meloeiro, desdobrou os graus de liberdade das interações significativas da variável qualitativa (posição das linhas portagotejadores) em relação aos níveis do demais fatores estudados (Tabela 4).

Para ${ }^{\circ}$ Brix a lâmina $\mathrm{L}_{1}$ não mostrou diferença estatística na posição das linhas de porta-gotejadores e nas doses de 
Tabela 4 Comparação de médias para SST e pH pelo teste de Tukey para o fator de posição das linhas porta-gotejadores (P), dentro dos níveis dos fatores de níveis de irrigação (L) e doses de potássio $(\mathrm{K})^{*}$

\begin{tabular}{|c|c|c|c|}
\hline Causas de variação & SST $(\%)$ & Causas de variação & $\mathrm{pH}$ \\
\hline $\mathrm{P}_{1}\left(\mathrm{~L}_{2} \mathrm{xK}_{0}\right)$ & $10,88 \mathrm{~A}$ & $\mathrm{P}_{1}\left(\mathrm{~L}_{1} \mathrm{xK}_{1}\right)$ & $6,05 \mathrm{~A}$ \\
\hline $\mathrm{P}_{2}\left(\mathrm{~L}_{2} \mathrm{XK}_{0}\right)$ & $8,16 \mathrm{~B}$ & $\mathrm{P}_{2}\left(\mathrm{~L}_{1} \mathrm{xK}_{1}\right)$ & $6,42 \mathrm{~B}$ \\
\hline $\mathrm{P}_{1}\left(\mathrm{~L}_{2} \mathrm{xK}_{2}\right)$ & $13,25 \mathrm{C}$ & $\mathrm{P}_{1}\left(\mathrm{~L}_{1} \mathrm{xK}_{3}\right)$ & $6,04 \mathrm{~A}$ \\
\hline $\mathrm{P}_{2}\left(\mathrm{~L}_{2} \mathrm{xK}_{2}\right)$ & $8,91 \mathrm{~B}$ & $\mathrm{P}_{2}\left(\mathrm{~L}_{1} \mathrm{xK}_{3}\right)$ & $6,41 \mathrm{~B}$ \\
\hline $\mathrm{P}_{1}\left(\mathrm{~L}_{3} \mathrm{xK}_{0}\right)$ & $8,73 \mathrm{~A}$ & $\mathrm{P}_{1}\left(\mathrm{~L}_{2} \mathrm{xK}_{0}\right)$ & $6,04 \mathrm{~A}$ \\
\hline $\mathrm{P}_{2}\left(\mathrm{~L}_{3} \times \mathrm{K}_{0}\right)$ & $10,53 \mathrm{~B}$ & $\mathrm{P}_{2}\left(\mathrm{~L}_{2} \mathrm{xK}_{0}\right)$ & $6,42 \mathrm{~B}$ \\
\hline $\mathrm{P}_{1}\left(\mathrm{~L}_{3} \mathrm{xK}_{2}\right)$ & 7,06 A & $\mathrm{P}_{1}\left(\mathrm{~L}_{2} \mathrm{xK}_{1}\right)$ & $6,06 \mathrm{~A}$ \\
\hline $\mathrm{P}_{2}\left(\mathrm{~L}_{3} \times \mathrm{K}_{2}\right)$ & $8,75 \mathrm{~B}$ & $\mathrm{P}_{2}\left(\mathrm{~L}_{2} \mathrm{xK}_{1}\right)$ & $6,37 \mathrm{~B}$ \\
\hline- & - & $\mathrm{P}_{1}\left(\mathrm{~L}_{3} \mathrm{xK}_{3}\right)$ & $6,37 \mathrm{~A}$ \\
\hline- & - & $\mathrm{P}_{2}\left(\mathrm{~L}_{3} \mathrm{xK}_{3}\right)$ & $6,00 \mathrm{~B}$ \\
\hline DMS & 1,50 & DMS & 0,29 \\
\hline
\end{tabular}

potássio estudadas. Para a lâmina $\mathrm{L}_{2}$ combinadas com as doses $\mathrm{K}_{0}$ e $\mathrm{K}_{2} \mathrm{o}{ }^{\circ}$ Brix diminui quando se utilizou linhas de portagotejadores enterradas, mostrando decréscimos do conteúdo de SST da ordem de 25 e $33 \%$ respectivamente, enquanto para a lâmina $\mathrm{L}_{3}$ aplicada de forma superficial e combinados com as mesmas dosagens $\left(\mathrm{K}_{0}\right.$ e $\left.\mathrm{K}_{2}\right)$ mostraram incrementos da ordem de 21 e $24 \%$ respectivamente.

$\mathrm{O}$ pH para os níveis de irrigação $\mathrm{L}_{1}$ e $\mathrm{L}_{2}$ combinadas comas doses $\mathrm{K}_{0}, \mathrm{~K}_{1}$ e $\mathrm{K}_{3}$, aumenta cerca de $6 \%$ nas linhas de portagotejadores enterradas, enquanto diminui para o nível de irrigação $\mathrm{L}_{3}$ combinada com a dose $\mathrm{K}_{3}$ também na ordem de $6 \%$ quando as linhas de porta-gotejadores estão na superfície.

Estes resultados sugerem que a irrigação por gotejamento superficial com lâminas de 417,32 mm e a irrigação por gotejamento enterrado com lâminas maiores de 279,60 mm pode repercutir de forma positiva no teor de SST e no $\mathrm{pH}$ dos frutos de melão, resultado proveitoso quando existe pouca demanda de água.

Aumentos no conteúdo de sólidos solúveis também foi observado por Pereira (1997) que encontrou média geral dos açúcares totais em híbrido de melão Gold Mine superior a 12 ${ }^{\circ}$ Brix com dose de $90 \mathrm{~kg} \mathrm{ha}^{-1}$ de $\mathrm{K}_{2} \mathrm{O}$. De acordo com Hubbard et al. (1990) fatores nutricionais, como deficiência de potássio, reduzem drasticamente a fotossíntese e, conseqüentemente, o acúmulo de sacarose no fruto, resultando em melões de baixa qualidade e, assim, os baixos valores de SST encontrados neste trabalho podem ser atribuídos ao baixo conteúdo inicial de potássio no solo (Tabela 1).

Muitos países adotam os valores do conteúdo de sólidos solúveis totais como uma referência de mercado para aceitabilidade, com variação mínima de 8 a 10 Brix. Alguns valores médios obtidos neste estudo estão abaixo do mínimo exigido pelo mercado; entretanto, se este caráter for analisado isoladamente como atributo de qualidade, poderá ser falho (Menezes, 1998). Os teores de sólidos solúveis totais encontrados no melão são praticamente iguais aos teores de sólidos solúveis produzidos nos melões do Brasil, aproximando-se dos valores encontrados por Prabhakar et al., (1985)

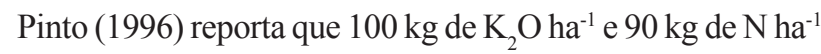
aplicados via água de irrigação em um Latossolo VermelhoAmarelo em Petrolina, PE, não proporcionaram diferenças significativas para a característica do teor de SST de frutos de melão.

O desdobramento das variáveis quantitativas para os níveis de irrigação e doses de potássio, pelo teste de regressão polinomial, é indicado na Tabela 5. Verifica-se que o efeito dos níveis de irrigação no conteúdo de SST pode ser representado por meios das estimativas das equações de primeiro grau, válido para os níveis de irrigação pertencentes ao intervalo $[276,60,417,32]$. As interações $\mathrm{L}\left(\mathrm{P}_{1} \mathrm{xK}_{1}\right)$ e L $\left(\mathrm{P}_{2} \mathrm{xK}_{2}\right)$ evidenciam maior conteúdo de SST na menor lâmina de irrigação estudada ( $\mathrm{L} 1=137,72 \mathrm{~mm})$, com média de $11^{\circ} \mathrm{Brix}\left(\mathrm{R}^{2}=0,99\right.$ e 80$)$, enquanto a interação $\mathrm{L}\left(\mathrm{P}_{2} \times \mathrm{K}_{0}\right)$ mostra maior conteúdo de SST na máxima lâmina de irrigação aplicada $\left(\mathrm{L}_{3}\right)$, atingindo $10^{\circ}$ Brix.

Tabela 5 Equações de regressão para ${ }^{\circ}$ Brix e $\mathrm{pH}$, para os fatores lâmina de irrigação (L) e dose de potássio (K)

\begin{tabular}{|c|c|c|c|}
\hline $\mathrm{CV}$ & Equação & & (Sig. $-p>F)$ \\
\hline \multicolumn{4}{|c|}{${ }^{o} \operatorname{Brix}(\%)$} \\
\hline $\mathrm{L}\left(\mathrm{P}_{1} \times \mathrm{xK}_{1}\right)$ & $\mathrm{Y}=12,418-0,008 \mathrm{~L}$ & $\mathrm{R}^{2}=0,99$ & $* *$ \\
\hline $\mathrm{L}\left(\mathrm{P}_{2} \mathrm{xK}_{0}\right)$ & $\mathrm{Y}=6,061+0,010 \mathrm{~L}$ & $\mathrm{R}^{2}=0,85$ & $* *$ \\
\hline $\mathrm{L}\left(\mathrm{P}_{2} \mathrm{XK}_{2}\right)$ & $\mathrm{Y}=12,249-0,009 \mathrm{~L}$ & $\mathrm{R}^{2}=0,80$ & $* *$ \\
\hline \multirow{2}{*}{$\mathrm{K}\left(\mathrm{P}_{1} \mathrm{xL}_{1}\right)$} & $\mathrm{Y}=7,935+0,287 \mathrm{~K}$ & $\mathrm{R}^{2}=0,55$ & $* *$ \\
\hline & $\mathrm{Y}=7,003+1,125 \mathrm{~K}-0,072 \mathrm{~K}^{2}$ & $\mathrm{R}^{2}=0,99$ & $* *$ \\
\hline $\mathrm{K}\left(\mathrm{P}_{2} \mathrm{XL}_{1}\right)$ & $\mathrm{Y}=8,389+0,184 \mathrm{~K}$ & $\mathrm{R}^{2}=0,87$ & $* *$ \\
\hline $\mathrm{K}\left(\mathrm{P}_{2} \mathrm{xL}\right)$ & $\mathrm{Y}=10,341-0,156 \mathrm{~K}$ & $\mathrm{R}^{2}=0,89$ & $* *$ \\
\hline \multicolumn{4}{|c|}{$\mathrm{pH}$} \\
\hline $\mathrm{L}\left(\mathrm{P}_{1} \mathrm{xK}_{3}\right)$ & $\mathrm{Y}=5,912+0,001 \mathrm{~L}$ & $\mathrm{R}^{2}=0,88$ & $* *$ \\
\hline $\mathrm{L}\left(\mathrm{P}_{2} \mathrm{XK}_{1}\right)$ & $\mathrm{Y}=6,578-0,001 \mathrm{~L}$ & $\mathrm{R}^{2}=0,88$ & $*$ \\
\hline $\mathrm{L}\left(\mathrm{P}_{2} \mathrm{xK}_{2}\right)$ & $Y=5,768+0,002 \mathrm{~L}$ & $\mathrm{R}^{2}=0,88$ & $* *$ \\
\hline $\mathrm{L}\left(\mathrm{P}_{2} \mathrm{XK}_{3}\right)$ & $\mathrm{Y}=6,708+0,001 \mathrm{~L}$ & $\mathrm{R}^{2}=0,56$ & $* *$ \\
\hline $\mathrm{K}\left(\mathrm{P}_{1} \mathrm{xL}_{2}\right)$ & $\mathrm{Y}=6,009+0,025 \mathrm{~K}$ & $\mathrm{R}^{2}=0,75$ & $* *$ \\
\hline
\end{tabular}

Ainda em relação a Tabela 5, os efeitos das doses de potássio sobre o SST do fruto de meloeiro podem ser representados pelas estimativas das equações de primeiro e segundo graus válidos para as doses de potássio no intervalo $[9,12]$ constatando-se aumento no conteúdo de SST com as maiores doses de potássio estudadas. As interações $\mathrm{K}\left(\mathrm{P}_{1} \mathrm{xL}_{1}\right)$ e $\mathrm{K}\left(\mathrm{P}_{2} \mathrm{xL}_{1}\right)$ podem alcançar conteúdo de $\mathrm{SST}$ até $11^{\circ}$ Brix com ajuste significativo $(\mathrm{p}<0,01)$ e coeficientes de determinação $\mathrm{R}^{2}$ de $0,55,0,99$ e 0,87 .

Com relação ao $\mathrm{pH}$ do fruto, o efeito das lâminas de irrigação pode ser representado através das estimativas das equações de primeiro grau, válido nos níveis de irrigação no intervalo [276,60, 417,32], em que se verifica um aumento do $\mathrm{pH}$ com o nível máximo de irrigação para todas as combinações mostradas, com valores de pH entre 6 e 7 com ajuste significativo $(p<0,01)$ e coeficiente de determinação $R^{2}=0,88$ 
e 0,56 , enquanto que a interação $\mathrm{L}\left(\mathrm{P}_{2} \times \mathrm{K}_{1}\right)$ mostra diminuição do $\mathrm{pH}$ com maiores lâminas de irrigação. Também os efeitos das doses de potássio sobre o $\mathrm{pH}$ do fruto de meloeiro podem ser representados através das estimativas das equações de primeiro e segundo graus validos para as doses de potássio no intervalo $[0,12]$ constatando-se aumento de $\mathrm{pH}$ com as doses mais altas de potássio, podendo atingir valores de até 6 unidades de $\mathrm{pH}$ com ajuste significativo $(\mathrm{p}<0,01)$ e coeficiente de determinação $\mathrm{R}^{2}$ de 0,75 , resultados diferentes aos encontrados por Cardoso (2002) que não encontrou diferenças significativas para valores de $\mathrm{pH}$ no melão rendilhado "Bônus 2", com $50 \mathrm{~kg} \mathrm{ha}^{-1}$ de $\mathrm{K}_{2} \mathrm{O}$ e $150 \mathrm{~kg}$ de $\mathrm{K}_{2} \mathrm{O} \mathrm{ha}^{-1}$ adicionados a $165,0 \mathrm{~kg} \mathrm{ha}^{-1} \mathrm{de} \mathrm{CO}_{2}$.

Esses resultados corroboram com os encontrados por Pew \& Garnwer (1983) os quais manifestam que excessiva irrigação pode prejudicar o crescimento das plantas de melão e, durante a colheita, o amadurecimento é mais propenso a queimaduras com prejuízos para o fruto, reduzindo o rendimento de mercado e o conteúdo de sólidos solúveis. Do mesmo modo, Pérez \& Cigales (2001) concluíram que a tendência foi diminuir de 10 para 9,2 o teor de SST ao se aumentar o conteúdo de água no solo, ou seja, o estresse hídrico (umidades com tensão acima de $35 \mathrm{kPa}$ ) reduziu o conteúdo de sólidos solúveis dos frutos de melão.

Welles \& Buitelaar (1988) verificaram que o conteúdo de sólidos solúveis diminui significativamente com a diminuição da área foliar, isto é, quanto maior a área foliar de plantas, maior também sua capacidade fotossintética. Soares (2001), encontrou valores médios de sólidos solúveis totais de frutos de melão variedade Cantalupensis Naud, híbrido Dom Carlos, que variaram de 12,8 a $9,8^{\circ}$ Brix para as combinações $\mathrm{K}_{3} \mathrm{~L}_{3}$

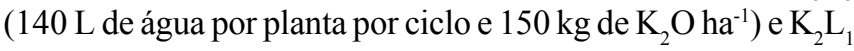
(70 L de água por planta por ciclo e $90 \mathrm{~kg}$ de $\mathrm{K}_{2} \mathrm{O} \mathrm{ha}^{-1}$ ), respectivamente.

O baixo resultado obtido neste trabalho, com relação ao SST, se deve, provavelmente, aos níveis inferiores de água aplicados na superfície, aos valores extremos de $\mathrm{K}_{2} \mathrm{O}(0$ e $12 \mathrm{~g}$ de $\mathrm{K}_{2} \mathrm{O}$ por planta), a condição de preparo dos canteiros e ao efeito de padronização de épocas de colheita de frutos sem completo desenvolvimento do tecido de abscisão (Bleinroth, 1994). Os valores de SST dos frutos abaixo de $5^{\circ}$ Brix podem ser devidos também à alta percentagem de água contida na polpa, causando diminuição por estar associado aos teores de sólidos pelo efeito de diluição (Wells \& Nugen, 1980).

\section{CONCLUSÕES}

1. Os níveis de potássio, as lâminas de irrigação e as posições dos gotejadores, além de algumas de suas interações, influenciaram significativamente nos parâmetros de qualidade dos frutos, decisivos na comercialização dos frutos de melão.

2. Os valores de sólidos solúveis totais se incrementam com as doses crescentes de potássio $\left(0,6\right.$ e $9 \mathrm{~g}$ de $\mathrm{K}_{2} 0$ por planta), diminuindo com a dose maior ( $12 \mathrm{~g}$ de $\mathrm{K}_{2} 0$ por planta) até valores próximos da dose mínima aplicada.
3. Os valores de sólidos solúveis totais aumentam até a aplicação de lâmina de 269,60 mm.

4. Os valores de $\mathrm{pH}$ experimentaram ligeiro incremento com a dose crescente de potássio aplicado.

5. Com nível intermediário de irrigação $(269,60 \mathrm{~mm})$, os frutos apresentaram maior valor de $\mathrm{pH}$; comparando-se com os níveis extremos (137,72 $\mathrm{mm}$ e 417,32 $\mathrm{mm}$ ), as plantas produziram frutos com maior $\mathrm{pH}$ nas linhas instaladas na subsuperfície.

6. Houve sensível incremento na acidez total titulável com o aumento das dose de potássio até $9 \mathrm{~g}$ de $\mathrm{K}_{2} \mathrm{O}$ por planta e, também, ligeiro decréscimo quando se aumenta o nível de irrigação para as linhas de gotejadores enterrados.

\section{LITERATURA CITADA}

Bar-Yosef, B. Advances in fertigation. Advances in Agronomy, New York, v. 65, p.1-77, 1999.

Bar-Yosef, B.; Sagiv, B. Response of tomatoes to N and water applied via a trickle irrigation system. I Nitrogen. Agronomy Journal, Madison, v.74, p. 633-637, 1986.

Bhella, H.S. Effect of trickle irrigation and black mulch on growth, yield and mineral composition of watermelon. Hort Science, Alexandria, v.23, p.123-125, 1988.

Bhella H.S.; Wilcox, G.E. Yield and composition of muskmelon as influenced by pretplant and trickle applied nitrogen. HortScience, Alexandria, v.21, n.1, p.86-88, 1986.

Bleinroth, E.W. Determinação do ponto de colheita. In: Netto, A.G. Melão para exportação: Procedimentos de colheita e pós-colheita. Brasília: FRUPEX, 1994.37p,

Bosland J.M.; Hughes, D.L.; Yamaguchi, M. Effects of glyphosine and triacontanol on growth, yield and soluble solids content of "PMR-45" muskmelons. HortScience, Alexandria, v.14, p.729-730, 1979.

Browkamp, J.C.; Angel, F.F.; Schales, F.D. Effect of weather conditions on soluble solids of muskmelon. Scientia Horticulturae, Lexington, v. 8, p.265-271, 1978.

Cardoso, S.S. 2002. Doses de $\mathrm{CO}_{2}$ e de potássio aplicados através de irrigação no meloeiro rendilhado (Cucumis melo L.) cultivado em ambiente protegido. Piracicaba: ESALQ, 2002. 101p. Tese Doutorado

Clough G.H.; Locascio, S.J.; Olson, S.M. Yield succesively cropped polyethylene mulched vegetables as affected by irrigation method and fertilization management. Journal of the American Society for Horticultural Science, v.115, p.884$887,1990$.

Coelho, R.D. Influência dos métodos de irrigação por sulco e gotejo na cultura do melão. In: Congresso Brasileiro de Irrigação e Drenagem, 4, 1978, Salvador. Resumos... Salvador: ABID, 1978.

Cohen, R.A.; Hicks, J.R. Effect of storage on quality and sugars in muskmelon. Journal of the American Society for Horticultural Science, Alexandria, v.111, n.4, p.553-557, 1986.

Dusi, A.N. Melão para exportação: Aspectos técnicos da produção - Brasília, DENACOOP/FRUPEX, 1992. 32p. DENACOOP, Série publicações Técnicas 1. 
Hariprakasa, M.; Srinivas, K. Effect of different levels of N, P, K on petiole and leaf nutrients, and their relationships to fruit yield and quality in muskmelon. Indian Journal of Horticultural Science, New Delhi, v.47, p.250-255, 1990.

Hubbard, N.L.; Pharr, D.M.; Huber, S.C. Sucrose metabolism in ripening muskmelon fruit as affected by leaf area. Journal of American Society for Horticultural Science, Alexandria, v.115, p.798-802, 1990.

Kiehl, E.J. Fertilizantes orgânicos. São Paulo, Editora Agronômica CERES. 1985, 147p.

Lippert L.F.; Legg, P.D. Appearance and quality characters in muskmelon fruit evaluated by a tencultivar diallel cross. Journal of the American Society of Horticultural Science, Alexandria, v.97, p.84-86, 1972.

Loy, J.B.; Wells, O.S. Response of hybrid muskmelons to polyethylene row covers and black polyethylene mulch. Scientia Horticulturae, Lexington, v.3, p.223-230, 1975.

Mancina, F.V. Rendimiento del cultivo de melón, bajo conditiones di riego por goteo en la region Laguneira. In: Seminário Latino-Americano sobre Riego por Goteo, 2., México, 1977. Anais: México: Torreon, 1977. 45p.

Medeiros, J.F. de; Pereira, F.A.C., Folegatti, M.V. Comparação entre a evaporação em tanque classe A padrão e o minitanque, instalados em estufa e estação meteorológica In: Congresso Brasileiro de Agrometereologia, 1997. Anais. Piracicaba: 1997.p.228 - 230

Menezes, J.B. Qualidade pós-colheita de melão tipo "Galia" durante a maturação e o armazenamento. Lavras: UFLA, 1996. 87p. Tese Doutorado

Pereira, A.J. Produção e qualidade de melão amarelo submetido à pulverização com duas fontes de cálcio. Lavras: UFLA, 1997, 46p. Dissertação Mestrado

Pérez Z.O.; Cigales, R.M. Tensión de humedad del suelo y fertilización nitrogenada en melón Cantaloupe, híbrido Ovation. Tepames, Colima, México. Agrociencia, v.35, p.479488, 2001.
Pew, W.D.; Garnwer B.R. Effects of irrigation practices on vine growth, yield, and quality of muskmelon. Journal American Society Horticultural Science, Alexandria, v.108, p.134-137, 1983.

Phene, C.J.; Beale, O.W. High-frequency irrigation for water nutrient management in humid regions. Soil Science Society of America Proceeding, Madison, v.40, n.3, p.430-436, 1976.

Pinto, M. Sistema de cultivo de melão com aplicação de fertilização via água de irrigação. EMBRAPA-CNPTSA-24, 1996. Circular Técnica, 36.

Pinto, M.; Soares, M.; Costa, D.; Brito, L.; Pereira, R. Aplicação de $\mathrm{N}$ e $\mathrm{K}$ via água de irrigação em melão. Horticultura Brasileira, Brasília, v.13, p.192-195, 1995.

Prabhakar, B.S.; Srinivas, K.; Shukla, V. Yield and quality of muskmelon (cv. Hara Madhu) in relation to soacing and fertilization. Progressive Horticulture, Chaubattia, v.17, n. 1., p.51-55, 1985.

Raij, B. van.; Cantarela, H.; Quaggio, J.A. Recomendações de adubação e calagem para o Estado de São Paulo. 2.ed. Campinas: IAC, 1996. 181p. Boletim, 100

Soares, A.J. Efeitos de três lâminas de irrigação e de quatro doses de potássio via fertirrigação no meloeiro em ambiente protegido. Piracicaba: ESALQ, 2001. 67p. Dissertação Mestrado

Sousa, V.F.; Coelho, E.F.; Souza, V.A.B. Freqüência de irrigação em meloeiro cultivado em solo arenoso. Pesquisa Agropecuária Brasileira, Brasília, v.34, n.4, p.659-664, 1999.

Welles, G.W.H.; Buitelaar, K. Factors affecting soluble solids content of muskmelon (Cucumis melo L.). Netherlands Journal of Agricultural Science, Amsterdam, v.36, p.239-246, 1988.

Wells, J.A.; Nugent, P.E. Effects of high soil moisture on quality of muskmelon. HorScience, St. Joseph, v. 15, p.258-259, 1980. 